\title{
O TRABALHO COLABORATIVO PARA UMA PRÁTICA CONTEXTUALIZADA E SIGNIFICATIVA NA EDUCAÇÃO FÍSICA ESCOLAR
}

\author{
Denise Ivana de Paula Albuquerque, Lívia Raposo Bardy \\ Universidade Estadual Paulista - UNESP, Departamento de Educação Física, Presidente Prudente, SP. E-mail: \\ denise@fct.unesp.br
}

\section{RESUMO}

Este artigo apresenta um estudo sobre o trabalho coletivo e teve por objetivo apresentar as concepções do trabalho colaborativo e destacar os aspetos que pudessem contribuir para uma prática pedagógica que identifica uma abordagem contextualizada e significativa. Foi desenvolvido no projeto, Educação Física Escolar e formação de professores: escola e universidade dialogando sobre a práxis pedagógica", do Núcleo de Ensino da Faculdade de Ciências e Tecnologia de Presidente Prudente. Os encaminhamentos metodológicos adotados indicam os pressupostos da pesquisa qualitativa. Os resultados apontaram que o trabalho coletivo e colaborativo deve ser estabelecido com a participação de todos os envolvidos no contexto escolar, de modo a direcionar e fundamentar práticas pedagógicas efetivas que preconizam uma educação de qualidade.

Palavras - chave: Trabalho Coletivo, Abordagem, Prática Pedagógica.

\section{THE COLLABORATIVE WORK FOR A CONTEXTUALIZED AND MEANINGFUL PRACTICE IN SCHOOL PHYSICAL EDUCATION}

\begin{abstract}
This article presents a study on the collective work and aimed to introduce the concepts of collaborative work and highlight the aspects which could contribute to a pedagogical practice that identifies a approach, contextualised and significant. It was developed in the project school physical education and training of teachers: school and university dialogue about the pedagogical praxis ", ", the Education Center of the Faculty of Science and Technology of Presidente Prudente. The methodological forwarding adopted indicate the assumptions of qualitative research. The results showed that the collective work must be established with the participation of all those involved in the school context, in order to direct and support effective pedagogical practices that advocate quality education.
\end{abstract}

Keywords: Collective Work, Approach, Pedagogical Practice 
INTRODUÇÃO

Historicamente, a Educação Física como área de formação, tem passado por transformações significativas, desde conceitos, metodologias, e interferências das diretrizes do marco regulatório, assim, fez-se necessária uma reformulação de seus princípios epistemológicos, que até então estiveram atrelados ao contexto histórico cultural.

O professor de Educação Física encontra pela frente muitos obstáculos em seu trabalho. Ele exerce sua função na escola, sendo um elemento de ligação importante entre os contextos educacional e social. Assim, é imprescindível não desconsiderar que o professor é fruto de um determinado contexto histórico e social, neste sentido, no seu papel de educador precisa explicitar este compromisso, não se atendo a questões técnicas de reprodução de conteúdos, mas sim, refletir sobre a construção de valores na escola e na sociedade.

Os Parâmetros Curriculares Nacionais ${ }^{1}$ de Educação Física trazem uma proposta que procura democratizar, humanizar e diversificar a prática pedagógica da área, buscando, ampliar, de uma visão apenas biológica, para um trabalho que incorpore as dimensões afetiva, cognitiva e sociocultural dos alunos. Incorpora, de forma organizada, as principais questões que o professor deve considerar no desenvolvimento do seu trabalho, subsidiando as discussões, os planejamentos e avaliações da prática pedagógica.

A profissão docente engloba um conhecimento pedagógico específico, um compromisso ético e moral e a necessidade de dividir a responsabilidade com outros agentes sociais, já que exerce influência sobre outros seres humanos e, portanto, não pode ser uma profissão meramente técnica de especialistas infalíveis que transmitem unicamente conhecimentos acadêmicos $^{2}$.

Ao tomar consciência da relevância dessa disciplina, é significativo que os profissionais que atuam nas aulas de Educação Física defendam os princípios que já estão legitimados nessa área para benefícios propostos, bem como, reivindicar prática politizada no contexto escolar, na qual a participação de todos deve ser garantida.

Para Roldão ${ }^{3}$, o trabalho colaborativo estrutura-se essencialmente como um processo de ações articuladas e pensadas de forma coletiva e colaborativa, que permite atingir os objetivos traçados para obter os melhores resultados.

Ao propor uma reflexão sobre o trabalho colaborativo dos professores polivalentes e professores de Educação Física, para a Educação Infantil e os primeiros anos do Ensino Fundamental, o presente estudo definiu como objetivo apresentar as concepções do trabalho colaborativo e destacar os aspetos que podem contribuir para uma prática pedagógica que 
identifica uma abordagem, Contextualizada e Significativa.

Contextualizada [...] parte do contexto da criança, desenvolvendo-se a partir da vivência dos alunos, relacionando-os com a sua realidade. Significativa [...] o professor mediará a formalização dos conceitos, para que o aluno consiga dar significado ao que está sendo aprendido; [...] cada aluno atuará conforme as suas habilidades e o seu interesse, resolvendo o problema de acordo com aquilo que mais se identifica ${ }^{4}$.

Essa abordagem pode ser considerada, como uma valiosa ferramenta para a formação continuada e em serviço de professores, uma vez que todas as atividades são elaboradas levando em consideração o uso prático das teorias estudadas, esse entendimento vem ao encontro das questões abordadas neste estudo, tendo em vista, que a problemática acerca do trabalho coletivo no contexto escolar é indispensável para a estruturação de processos educativos que visem à apropriação e a contextualização de conhecimentos, para fortalecer e consolidar o ensino de qualidade.

A cooperação entre os elementos de um grupo, na opinião de Pugach e Johnson (apud Milheiro ${ }^{5}$ ), visa cumprir quatro papéis, são eles:

(I) apoiar ou suportar os colegas que enfrentam dificuldades; (II) facilitar ou promover o desenvolvimento profissional dos colegas; (III) informar e partilhar experiências; (IV) prescrever um conjunto de medidas a ser implementadas por outros colegas, que beneficiam de uma ajuda complementar.

Este estudo sobre o trabalho coletivo e colaborativo foi desenvolvido a partir da proposta do projeto "Educação Física Escolar e formação de professores: escola e universidade dialogando sobre a práxis pedagógica", do Núcleo de Ensino da Faculdade de Ciências e Tecnologia de Presidente Prudente, contemplando as ações previstas no referido projeto.

\section{METODOLOGIA}

O delineamento metodológico foi embasado pelos referenciais qualitativos. Ao analisar os dados de forma qualitativa, procurou-se uma equalização a fim de que os resultados fossem fidedignos. Segundo Lüdke e André ${ }^{6}$, analisar o conjunto de dados qualitativos significa trabalhar todo o material obtido durante a pesquisa, ou seja, organizar o material coletado, identificando tendências e padrões relevantes nos mesmos.

O estudo foi desenvolvido na Escola Municipal EMEIF, Rosana Negrão, e está vinculado ao projeto do Núcleo de Ensino, mencionado anteriormente. Este projeto tem um caráter de natureza interdisciplinar, é constituído por um docente do Departamento de Educação Física, alunos 
bolsistas e colaboradores da Faculdade de Ciências e Tecnologia da UNESP de Presidente Prudente, e ainda por colaboradores externos. O estudo foi avaliado e aprovado pelo Comitê de Ética da UNESP de Presidente Prudente, número CAAE: 3668.9414.5.0000.5402.

A proposta foi desenvolver diferentes atividades relacionadas as manifestações da cultura corporal com as crianças, por meio de vivências, reflexões e registros. Também foram promovidas atividades de estudo junto dos professores, coordenador e diretor da escola, com encontros que buscavam promover interações e a troca de informações entre a equipe do projeto, alunos e professores da rede pública de ensino, de forma a estreitar os vínculos entre a universidade (UNESP - Campus de Presidente Prudente) e a escola pública, a fim de que os envolvidos no processo possam ter conhecimento das discussões que balizam as intervenções presentes na práxis-pedagógica dos bolsistas.

\section{RESULTADOS}

Nos encontros realizados com os professores, nas Horas de Trabalho Coletivo e Pedagógico (HTPC), e coordenados pela pesquisadora e colaboradores do projeto, a dinâmica consistiu em discussão em grupo sobre os encaminhamentos das atividades relacionadas a Educação Física, em consonância com o processo de ensino e aprendizagem dos conteúdos de outras áreas. Foram apresentadas algumas dificuldades no que diz respeito aos domínios de conteúdos da referida disciplina, pelos professores polivalentes:

"Na prática eu me vejo dando atividades repetitivas, por falta de conhecimento amplo da disciplina".

"As crianças escolhem o que querem fazer ou brincar".

"O tradicional: atividades livres com bolas, arcos e cordas e pronto".

Para Almeida Junior ${ }^{7}$, as intervenções das professoras nas aulas são poucas, restringem-se a entregar a bola, a informar os alunos sobre o tempo restante das aulas, ou a resolver algum desentendimento entre eles. Os relatos referentes à prática pedagógica dos professores polivalentes revelam como as aulas estavam sendo desenvolvidas e que tipo de formação os alunos recebem. Estas práticas indicam situações pedagogicamente pouco organizadas e controladas, porém vividas pelos alunos. Como é possível observar pelo relato de um aluno:

"A gente sempre brinca de qualquer coisa" 
Para Oliveira ${ }^{8}$ não podemos conceber as atividades desenvolvidas pelas professoras como "aulas de Educação Física" e sim como momentos de descanso e como recurso metodológico para a aprendizagem de outros conteúdos.

A partir desses relatos, o trabalho com os professores e os gestores, foi pautado para o desenvolvimento e ações que pudessem agregar os diferentes conhecimentos. O desafio foi possibilitar um novo olhar a estrutura vigente, e assim ao longo do desenvolvimento do projeto, foram debatidas questões relacionadas a:

$>$ a organização curricular;

$>$ o papel dos agentes formadores ( professores, gestores, e outros segmentos);

a gestão em uma perspectiva democrática;

o trabalho coletivo;

a propositura de projetos interdisciplinar.

Desse movimento, desencadeado pela necessidade de se valorizar as diferentes práticas educativas presentes naquele contexto escolar, emergiu uma compreensão da necessidade de construção de uma escola comprometida com a uma educação de qualidade, na qual todos têm sua importância e responsabilidades. Para Freire ${ }^{9}$ não há prática educativa, sem espaço educativo, e nesses espaços deve ser garantido o trabalho coletivo.

Ao partilharem as experiências e conhecimentos entre si, os profissionais, envolvidos num processo colaborativo, devem estar sensibilizados para a importância de partilharem um conjunto de crenças, atitudes e valores acerca da escola, dos objetivos de ensino e da aprendizagem A partilha de responsabilidades é caracterizada com a participação ativamente de todos os docentes nas inúmeras atividades escolares como, por exemplo, nas reuniões, contribuindo com conhecimentos e opiniões e atribuem-se a responsabilidade ao nível das decisões ${ }^{5}$.

Os resultados dessas intervenções foram observados, através de propostas de projetos, como, por exemplo: Conhecendo o mundo com o futebol; O Brasil e suas danças, Aprender brincando.

\section{DISCUSSÃO}

Ainda, há muito o que fazer, para atender alguns princípios do trabalho colaborativo , que segundo Roldão ${ }^{3}$, para que exista verdadeiramente um trabalho colaborativo no contexto escolar, os atores desse cenário, têm que estabelecer um plano estratégico e criar metodologicamente a finalidade que orienta as suas tarefas e assim organizar adequadamente todos os dispositivos dentro do grupo para que, permitam: 
(i) Alcançar com mais sucesso o que se pretende (as aprendizagens pretendidas);

(ii) Ativar, o mais possível, as diferentes potencialidades de todos os participantes (...) de modo a envolvê-los e a garantir que a atividade produtiva não se limita a alguns;

(iii) Ampliar o conhecimento construído por cada um, pela introdução de elementos resultantes da interação com todos os outros ${ }^{3}$.

Partindo dessas reflexões é importante salientar que o professor de Educação Física, também deve em sua prática cotidiana, assumir os pressupostos teóricos que preconizam um processo de ensino e aprendizagem em uma abordagem contextualizada e significativa, e juntamente com seus pares promover uma educação fundamentada nos pilares da qualidade.

Ao desenvolver este estudo, pretendeu-se abordar pontos importantes referentes ao tema em questão. As propostas apontadas pelo marco regulatório nas diretrizes da Educação contemporânea para a formação crítica e reflexiva dos alunos identificam a importância do trabalho colaborativo. Conforme aponta o Artigo 10ㅇ da Resolução no 4 de 2010 (Conselho Nacional de Educação/Ministério da Educação), que define as Diretrizes Curriculares Nacionais Gerais para a Educação Básica, no Art. 10. " a exigência legal de definição de padrões mínimos de qualidade da educação traduz a necessidade de reconhecer que a sua avaliação associa-se à ação planejada, coletivamente, pelos sujeitos da escola".

$\S 1$ o O planejamento das ações coletivas exercidas pela escola supõe que os sujeitos tenham clareza quanto:

II - à relevância de um projeto político-pedagógico concebido e assumido colegiadamente pela comunidade educacional, respeitadas as múltiplas diversidades e a pluralidade cultural;

III - à riqueza da valorização das diferenças manifestadas pelos sujeitos do processo educativo, em seus diversos segmentos, respeitados o tempo e o contexto sociocultural.

É nessa dimensão que trabalho coletivo se destaca, destarte a importância dos diversos atores do contexto escolar, o papel do professor se sobressai, no que tange a articulação da teoria e prática necessária para uma prática pedagógica fundamentada em pressupostos, que favoreçam a retroalimentação do conhecimento concreto contextualizado com observações do cotidiano escolar, levando à construção e significação de novos saberes. Assim, a prática passa de mero campo de aplicação, a campo de produção do conhecimento, na medida em que a atividade 
profissional envolve aprendizagens, que vão além da simples aplicação do que foi estudado e os saberes construídos no fazer passam a ser objeto de valorização sistemática ${ }^{10}$.

Ainda de acordo com Veras (2010), o trabalho coletivo constitui um conjunto de ações que enfatizam desde a necessidade do resgate e a restruturação dos conteúdos, à implementação de um ensino baseado em competências ancoradas pela inserção de temas transversais que norteiam a contextualização.

\section{CONCLUSÃO}

A realidade brasileira contemporânea aponta para a necessidade da construção de um novo modelo de escola; é o resultado de um amplo e recente movimento de renovação pedagógica, pensando na indigência de alçar o ensino a um patamar democrático real, uma vez que o direito à educação não se restringe ao acesso à escola. Este, sem a garantia de permanência e de apropriação e produção do conhecimento pelo aluno, não significa, necessariamente, o usufruto do direito à educação ${ }^{11}$.

A escola tem de ser a construtora do saber, com justiça social, promovendo a discussão de temas contextualizados coerentes com os conteúdos desenvolvidos. Esses conceitos podem ser entendidos como eixos integradores do desenvolvimento curricular que irão nortear as práticas pedagógicas. A transformação da escola ocorre lentamente. Pequenas ações, mas, continuadas são melhores no processo de mudança. Somente a ação direta de cada professor, de cada gestor, de cada turma, de cada escola poderá tornar a educação um processo enriquecedor ${ }^{12}$.

A propósito de seus objetivos e conteúdos, a Educação Física deve conclamar para área, uma concepção de educação que venha ao encontro das expectativas do contexto social e responder à renovação educacional. Portanto ao assumir esse papel não deve restringir as ações pedagógicas à prática de exercícios de certas habilidades e destrezas, mas também levar os alunos a refletir sobre suas possibilidades corporais, com autonomia, de modo a exercê-las de maneira social e culturalmente significativas. Esses preceitos poderão ser alcançados a partir de um trabalho inter e multidisciplinar no contexto escolar.

Nesse sentido, foi possível observar que ocorreram algumas mudanças em relação ao trabalho coletivo entre os professores envolvidos, bem como sobre a melhora na qualidade das atividades propostas para a disciplina de Educação Física. Isso pode sinalizar que as ações colaborativas devem ser implementas, a partir das expectativas que emanam desse contexto tão significativo. 


\section{REFERÊNCIAS}

1. BRASIL. Ministério da Educação e do Desporto. Secretária de Educação Fundamental. Parâmetros Curriculares Nacionais. Brasília. 1998.

2. IMBERNÓN, F. Formação Docente e Profissional: formar-se para a mudança e a incerteza. São Paulo, Cortez, 2000.

3. ROLDÃO, M. Colaborar é preciso: questões de qualidade e eficácia no trabalho dos professores, in Dossier: Trabalho colaborativo dos professores, Revista Noesis, n.o 71, 24-29 Lisboa, 2007.

4. SCHLÜNZEN, E. T. M. Mudanças nas práticas pedagógicas do professor: criando um ambiente construcionista, contextualizado e significativo para crianças com necessidades especiais físicas. Tese de Doutorado. PUC/SP. São Paulo, 2000.

5. MILHEIRO, R. I.A.G.L. Trabalho Colaborativo entre docentes - um estudo de caso. Dissertação de Mestrado em Ciências da Educação - Supervisão Pedagógica. ESCOLA SUPERIOR DE EDUCAÇÃO JOÃO DE DEUS, Lisboa, 2013.

6. LÜDKE, M. \& ANDRÉ, M.E.D.A. Pesquisa em educação: abordagens qualitativas, São Paulo, EPU, 1986.

7. ALMEIDA JUNIOR, O. A prática pedagógica das professoras de 1a a 4a $^{\text {a }}$ series nas aulas de educação física. 2000. 35p. Trabalho de Conclusão de Curso (Educação Física) - Departamento de Educação/Instituto de Biociências/UNESP.

8. OLIVEIRA, G.R. A Educação Física nas séries iniciais: espaço de fada ou de fato? 2002. Dissertação (Mestrado em Ciências e Práticas Educativas) -Universidade de Franca.

9. FREIRE, Paulo. Pedagogia da autonomia: saberes necessários à prática educativa. Rio de Janeiro : Paz e Terra, 1997.

10.VERAS, M. J. C. Referenciais Curriculares do Ensino Fundamental: Matemática , Ciências da Natureza e Diversidade Sociocultural. Governo do Estado da Paraíba. Secretaria de Educação e Cultura. Gerência Executiva da Educação Infantil e Ensino Fundamental. - João Pessoa: SEC/Grafset, 2010.

11. ALVES, R. Não esqueça as perguntas fundamentais. In: Folha de S.Paulo, Caderno Sinapse, 25/2/2003.

12. GADOTTI M. Perspectivas Atuais da Educação. Porto Alegre, 2000. 